\title{
Ovarian antibodies as detected by indirect immunofluorescence are unreliable in the diagnosis of autoimmune premature ovarian failure: a controlled evaluation
}

\author{
Judy A Novosad, Sophia N Kalantaridou, Zhi-Bin Tong and \\ Lawrence M Nelson*
}

\begin{abstract}
Address: Section on Women's Health Research, Developmental Endocrinology Branch, National Institute of Child Health and Human Development, National Institutes of Health, Bethesda, Maryland, USA

Email: Judy A Novosad - janovosad@aol.com; Sophia N Kalantaridou - kalantas@cc1.nichd.nih.gov; Zhi-Bin Tong - Tongz@cc1.nichd.nih.gov; Lawrence M Nelson* - Lawrence_Nelson@nih.gov

* Corresponding author
\end{abstract}

Published: 17 March 2003

BMC Women's Health 2003, 3:2

This article is available from: http://www.biomedcentral.com/1472-6874/3/2

(C) 2003 Novosad et al; licensee BioMed Central Ltd. This is an Open Access article: verbatim copying and redistribution of this article are permitted in all media for any purpose, provided this notice is preserved along with the article's original URL.
Received: 23 December 2002

Accepted: 17 March 2003

\begin{abstract}
Background: Ovarian antibodies as detected by indirect immunofluorescence have been used to detect ovarian autoimmunity, but to our knowledge the rate of false positive findings using this method has never been reported.

Methods: Here we examine whether a commercially available ovarian antibody test system, using cynomologous monkey ovary, might be useful in the diagnosis of autoimmune premature ovarian failure. The test was performed in a blinded manner in 26 young women with $46, X X$ spontaneous premature ovarian failure, in 26 control women with regular menstrual cycles (matched for age, race, and parity) and 26 control men (matched for age and race). We also compared the frequency of other autoantibodies associated with ovarian autoimmunity.
\end{abstract}

Results: As a group young women with premature ovarian failure had an increased incidence of thyroid and gastric parietal cell autoimmunity $(p<0.05)$. Unexpectedly, however, nearly one third $(31 \%)$ of normal control women had ovarian antibodies using the commercially available test. One half of young women with premature ovarian failure were found to have ovarian antibodies $(P=$ 0.26). In our own laboratory we found similar results and we were unable to improve the specificity of the test. None of 26 men were found to have ovarian antibodies $(P<0.00 I)$.

Conclusion: Since approximately one third of normal women were found to have ovarian antibodies using the system under study, we conclude that ovarian antibodies as detected by this indirect immunofluorescence method have poor specificity. The specificity of any ovarian antibody test should be established before it is used clinically.

\section{Background}

Autoimmunity is a well-established mechanism of premature ovarian failure. [1-4]. It has been suggested that the presence of ovarian antibodies may be helpful in the diagnosis of ovarian autoimmunity $[5,6]$. However, presently there is no validated serum marker that can establish a diagnosis of autoimmune premature ovarian failure with certainty [7]. Young women can experience ovarian failure by several mechanisms other than autoimmunity [8]. A false positive diagnostic test indicating autoimmunity as 
the mechanism of spontaneous premature ovarian failure could put young women at risk for inappropriate therapy. Such therapy could have serious consequences, such as the development of osteonecrosis[4]

Some women with premature ovarian failure have ovarian follicles that function intermittently $[9,10]$. and pregnancies have occurred after the diagnosis of premature ovarian failure [11-14]. Clinicians are in need of an accurate method for the diagnosis of autoimmune oophoritis, a test with proven sensitivity and specificity [15]. Here we conduct an investigation to determine whether a commercially available ovarian antibody test (Immunodiagnostic Laboratories, Inc., San Leandro, CA) might be useful in the diagnosis of autoimmune premature ovarian failure. We performed the test in women with premature ovarian failure, women with normal ovarian function, and in men. We found that this commercially available test has a high incidence of false positives. Therefore, this test would not be expected to be useful in the diagnosis of autoimmune premature ovarian failure.

\section{Methods \\ Patients and Controls}

By local advertisement we recruited 26 control women with regular menstrual cycles (matched for age and parity to our patients) and 26 control men (matched for age). The controls were also matched to patients for race. We recruited patients with spontaneous premature ovarian failure by letters to physicians and notices in medical journals. The National Institute of Child Health and Human Development Institutional Review Board approved the protocol. We diagnosed premature ovarian failure in women who before the age of 40 had experienced amenorrhea in association with serum FSH levels greater than $40 \mathrm{mIU} / \mathrm{mL}$ (confirmed on two separate occasions, at least one month apart). Twenty-six patients with premature ovarian failure participated in this study (median age of 33 years, range 18-39 years). The women had been diagnosed at a median age of 30 years (range 15-38 years). The median time since diagnosis was 2 years (range 0.3312 years). All patients had a normal karyotype and had no history of chemotherapy or radiation. Six patients (26\%) had hypothyroidism, one patient had Addison disease, and one patient had Raynaud syndrome.

\section{Ovarian Antibodies}

We sent blinded specimens to Immunodiagnostic Laboratories, Inc. (San Leandro, CA) to be tested for ovarian antibodies using an indirect immunofluorescence test system supplied by Scimedx Inc. (Denville, NJ). The kit includes frozen sections of cynomologous monkey ovary as tissue substrate, a positive control of human serum known to contain antibodies against the zona pellucida, a negative control serum, and fluorescein isothiocyanate
(FITC) conjugated goat antibodies against human immunoglobulins including IgG, IgM and IgA. Binding of antibody to the zona pellucida at a 1:10 dilution was reported by the laboratory on a scale of 0 to $3+$ according to the intensity of fluorescence: 0 , negative; $1+$, weak; $2+$ moderate or $3+$ strong fluorescence (Figure 1 ).

We also tested serum in our own laboratory using this same test system (Scimedx, Inc., Denville, NJ). Aliquoted serum samples of patients and controls were stored at $80^{\circ} \mathrm{C}$. After thawing at room temperature, serum samples were diluted 1:10 with PBS. We confirmed the adequacy of monkey ovary sections from individual lots in an unblinded manner before using them. For each experiment slides of monkey ovary with the same lot number were allowed to equilibrate to room temperature. Twenty microliters of blinded sample were applied to the tissue substrate slides. A slide containing positive and negative controls was run unblinded with each experiment. Slides were placed into a moist covered chamber and incubated for 30 minutes at room temperature. Next, the slides were washed in PBS for three 10-minute soaks. After blotting the slides, $20 \mathrm{uL}$ of FITC-conjugated goat antibodies against human immunoglobulins was delivered to each sample and slides were again incubated in the moist chamber for 30 minutes. The washings and blotting were repeated as above. Mounting medium and a coverslip were applied. The slides were kept in a dark moist chamber until evaluated using a Zeiss Axiophot Fluorescent Microscope (Carl Zeiss Inc., Thornwood, NY) at $40 \times$ magnification with emission at $400 \mathrm{nM}$ and excitation at 520-560 nM. We graded fluorescence of the zona pellucida on the same 0 to $3+$ scale as noted above.

\section{Reproducibility}

To evaluate the reproducibility of the test we selected four patient samples previously determined by this technique to be $0,1+2+$, and $3+$ for zona pellucida antibodies. In a blinded manner, we tested each sample 15 times ( 5 tests each on three separate days).

\section{Other Autoantibodies}

Antinuclear antibody (ANA) titer was determined by indirect immunofluorescence using Hep-2 substrate. Rheumatoid factor was determined by latex agglutination. Antiparietal cell antibodies were measured by indirect immunofluorescence using rat stomach (Smith Kline Beecham Clinical Laboratories, Van Nuys, CA). Antithyroid peroxidase (anti-TPO) binding activity was determined by a radiobinding assay using Iodine ${ }^{125}$ labelled human recombinant thyroid peroxidase (Nichols Institute, San Juan Capistano, CA). 

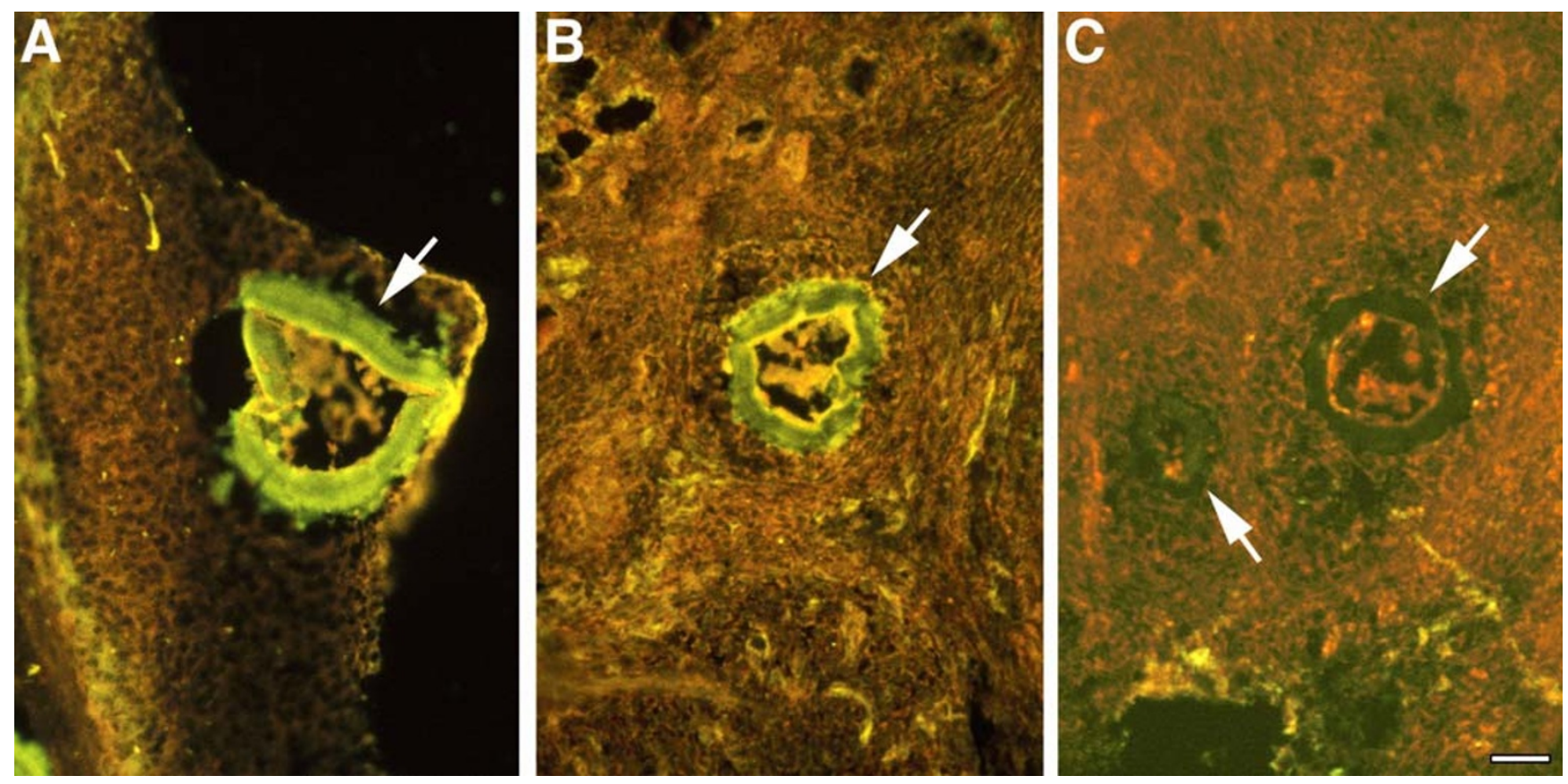

Figure I

Indirect immunofluorescence using cynomologous monkey ovary. Shown are a representative sample of a positive control (A), a 3+ positive patient sample (B), and a negative control (C). The scale bar represents $50 \mu \mathrm{m}$. Each arrow points to a zona pellucida. Images were prepared in our laboratory using a commercially available test system (Scimedx, Inc., Denville, $\mathrm{NJ})$.

\section{Statistics}

We used the Fischer exact test, chi-square, and the Spearman rank correlation test as appropriate. We used onetailed tests to look for an increase in autoantibody as compared to controls and we set $P<0.05$ as significant. Statistical analysis was performed using Sigma Stat Software (Jandel Scientific, San Rafael, CA).

\section{Results}

\section{Ovarian antibodies}

\section{By commercial laboratory}

Eight of 26 control women (31\%) and 13 of 26 women with spontaneous premature ovarian failure $(50 \%)$ had ovarian antibodies as detected by the commercial labora- tory (Table 1$)$. The frequencies were not significantly different $(P=0.26$, chi-square test $)$.

\section{By our own laboratory}

When we evaluated these same samples for ovarian antibodies in our own laboratory we obtained similar results. Twelve of 26 patients (46\%) with premature ovarian failure had ovarian antibodies versus 10 of 26 control women (38\%) $(P=0.78$, chi-square test; Table 1$)$.

\section{Reproducibility}

We could not reliably reproduce the four categories of ovarian antibody test grading. Although our results correlated with the known graded samples $(r=0.72, P<0.05)$, the $1+$ readings were reproduced in only 8 of the 15 tests 
Table I: Results of ovarian antibody tests in women with premature ovarian failure (POF) and control women (CTRL) matched for age and parity.

\begin{tabular}{|c|c|c|c|c|c|c|}
\hline \multirow[b]{2}{*}{ Sample } & \multicolumn{2}{|c|}{ Commerciala } & \multicolumn{2}{|c|}{$\mathrm{NIH}^{\mathrm{b}}$} & \multicolumn{2}{|c|}{ NIH Revised Methodc } \\
\hline & POF & CTRL & POF & CTRL & POF & CTRL \\
\hline I & $1+$ & - & $1+$ & $1+$ & + & - \\
\hline 2 & - & - & - & $1+$ & - & - \\
\hline 3 & $1+$ & $1+$ & $1+$ & $1+$ & + & + \\
\hline 4 & - & - & - & $1+$ & - & + \\
\hline 5 & - & $1+$ & - & $2+$ & - & + \\
\hline 6 & - & - & - & - & - & + \\
\hline 7 & - & $2+$ & $1+$ & $3+$ & + & - \\
\hline 8 & $1+$ & - & $1+$ & - & + & + \\
\hline 9 & $1+$ & - & $2+$ & - & + & - \\
\hline 10 & $1+$ & - & - & - & + & - \\
\hline 11 & $1+$ & - & $3+$ & - & + & + \\
\hline 12 & - & $1+$ & - & - & - & - \\
\hline 13 & - & - & - & - & - & + \\
\hline 14 & - & $1+$ & - & $1+$ & + & - \\
\hline 15 & $1+$ & $1+$ & $1+$ & $2+$ & - & - \\
\hline 16 & - & $1+$ & - & - & - & + \\
\hline 17 & - & - & - & - & - & - \\
\hline 18 & $1+$ & - & $1+$ & $2+$ & + & + \\
\hline 19 & $1+$ & - & $1+$ & - & + & - \\
\hline 20 & - & - & - & - & - & + \\
\hline 21 & - & $1+$ & - & - & - & - \\
\hline 22 & $1+$ & - & $1+$ & $1+$ & + & - \\
\hline 23 & $1+$ & - & - & - & - & - \\
\hline 24 & - & - & - & - & + & - \\
\hline 25 & $2+$ & - & $3+$ & - & + & + \\
\hline 26 & $1+$ & - & $1+$ & - & + & - \\
\hline Total (+) & 13 & 8 & 12 & 10 & 14 & 11 \\
\hline
\end{tabular}

aResults by commercial laboratory b Results by our laboratory using the commercial method cResults by our laboratory with outcome measure as simply positive $(+)$ or negative $(-)$

Table 2: Reproducibility of the ovarian antibody grading system.

\begin{tabular}{lcccc}
\hline & 0 & & Known Graded Sample & \\
& & $1+$ & $2+$ & \\
Test Result & & & & \\
& & & 2 & 2 \\
0 & 13 & 6 & 2 & 0 \\
$1+$ & 1 & 1 & 2 & 1 \\
$2+$ & 1 & 0 & 9 & 12 \\
$3+$ & 0 & 53 & 13 & 80 \\
Percent Reproduced & 87 & 13 & \\
\hline
\end{tabular}

$(53 \%)$ and the $2+$ readings were reproduced in only 2 of the 15 tests $(13 \%)$ (Table 2). In contrast, the 0 and $3+$ readings were reproduced in $13(87 \%)$ and $12(80 \%)$ of the 15 respective tests (Table 2 ).

\section{Efforts to improve the test}

Because the 1+ and 2+ readings had poor reproducibility, we were concerned that this inaccuracy might have impaired our ability to detect a difference between patients and control women. We therefore redefined the outcome measure to be read simply as positive $(+)$ or negative $(-)$. 
Table 3: Frequency of other selected autoantibodies in women with premature ovarian failure (POF) and control women matched for age and parity.

\begin{tabular}{lcc}
\hline Antibody Test & Women with POF $n=26$ & Control Women $^{\mathrm{a}} \mathrm{n}=26$ \\
\hline Antithyroid peroxidase $\geq 0.9 \mathrm{u} / \mathrm{mL}$ & $9(35)^{\mathrm{b}}$ & $3(12)$ \\
Antiparietal Cell $\geq 1: 10$ & $4(15)^{\mathrm{b}}$ & $0(0)$ \\
ANA $\geq 1: 80$ & $5(19)$ & $6(23)$ \\
Rheumatoid Factor $\geq 1: 320$ & $2(8)$ & $0(0)$ \\
\hline
\end{tabular}

a Values are the number of positive tests, in parentheses are percent positive bSignificantly different from controls $(P<0.05$, Fischer's exact test).

Positive was defined as the presence of homogeneous fluorescence on the zona pellucida above background and negative was defined as any fluorescence less than this. Tests were then repeated using serum from the 26 patients and 26 control women. We were unable to demonstrate a significant difference using the revised outcome measure. Patient serum was positive in 14 of 26 samples (54\%) and control serum was positive in 11 of 26 samples (42\%) (Table 1). When we tested the sera on three separate occasions with this method, we found 9 patient sera (35\%) and 6 control sera $(23 \%)$ to be consistently positive for zona pellucida antibody $(P=0.38)$.

We were unable to improve the test by using higher dilutions of serum (1:20, 1:40, and 1:80). All 26 patients and all 26 controls were negative for ovarian antibodies at 1:20. The positive control sample was positive at 1:40 and negative at 1:80.

\section{Specificity}

To evaluate the specificity of the test we compared sera from 26 normal women with sera from 26 normal men matched for age. The tests were performed at 1:10 dilution using the positive and negative outcome measure as discussed above. Women were significantly more likely to have ovarian antibodies than men. Eleven of 26 normal women $(42 \%)$ had ovarian antibodies whereas none of the 26 normal men had these antibodies $(\mathrm{P}<0.001)$. These findings were confirmed in a separate experiment (9/26 versus $0 / 26, \mathrm{P}<0.002)$.

\section{Other Auto-antibodies}

Results of other antibody tests are shown in Table 3. Women with spontaneous premature ovarian failure were significantly more likely than control women to have parietal cell antibodies $(\mathrm{P}<0.05$, Fischer's exact test $)$ and thyroid peroxidase antibodies $(\mathrm{P}<0.05$, Fischer's exact test).

\section{Discussion}

There is evidence to suggest that some patients with spontaneous premature ovarian may have clinically significant circulating ovarian antibodies. In a seminal study report- ed in 1979, Coulam and Ryan demonstrated that patients with premature ovarian failure, as a group, have ovarian antibodies present in their sera as determined by immunoprecipitation of radiolabeled human ovarian proteins [16]. However, the identity of these specific ovarian antigen(s) remains unknown. It should pointed out, however, that immunoblotting studies have failed to reveal a consistent pattern of binding using the sera of patients with premature ovarian failure[7].

Presently, there is no proven sensitive and specific serum test to confirm that a woman has ovarian failure on an autoimmune basis[7]. Histologic evaluation of the ovary is the only way to diagnose autoimmune oophoritis with certainty [17]. Nonetheless, some clinicians currently use commercial ovarian antibody tests for the diagnosis of autoimmune premature ovarian failure and make treatment recommendations based on these findings. This approach can have severe adverse consequences such as the development of osteonecrosis related to glucocorticoid therapy[4]. Here we demonstrate that detection of ovarian antibodies by indirect immunofluorescence using one specific commercial test system has poor specificity as a diagnostic test. The test is positive in nearly one-third of normal women. Therefore, the test is not a useful diagnostic marker of autoimmune premature ovarian failure.

We found that women with premature ovarian failure are significantly more likely to have positive thyroid peroxidase and parietal cell autoantibodies than women with normal ovarian function. In this regard our findings are in agreement with previous studies [18-20]. In contrast to one previous study, however [21], we did not find a significantly higher prevalence of antinuclear antibodies in women with premature ovarian failure.

Because little is known about the pathophysiology of human autoimmune oophoritis, experimental animal models have been used to gain insight into possible mechanisms $[22,23]$. The fact that we found an increased frequency of thyroid and gastric parietal cell antibodies in our patients suggests similarity to a model of autoimmune ovarian failure that can be induced in certain strains 
of mice by performing neonatal thymectomy. These mice also develop autoimmunity against thyroid and gastric parietal cells [22]. It is well established that these mice with ovarian autoimmunity also develop circulating autoantibodies against the oocyte cytoplasm, the zona pellucida, and against steroid producing cells [22]. While we found evidence that one half of our patients had specific antibodies directed against the zona pellucida, we did not find any consistent pattern of immunofluorescence to suggest that our patients had antibodies directed against the oocyte cytoplasm or the steroid producing cells of the ovary. It is noteworthy that immune serum from mice with ovarian autoimmunity reacts specifically with an oocyte-specific protein called MATER $[24,25]$. We have subsequently identified the homologous human MATER gene and protein[26] In ongoing work we are evaluating the value of MATER antibodies as a marker for autoimmune ovarian failure in women.

The fact that we did not detect ovarian antibodies binding to the zona pellucida in any of 26 men $(p<0.001)$ is intriguing. This finding supports proposals that pre-B cells undergo positive selection directed by the presence of surface heavy chains with low albeit sufficient affinity to the autoantigen. It appears then, that men, lacking the specific ovarian self-antigen, fail to provide positive selection for these pre- $\mathrm{B}$ cells clones. Also, this finding suggests that the detection system is specific for zona pellucida, and that further refinement of the assay system by using pure human recombinant zona pellucida protein might be useful. Sacco and Moghissi detected zona pellucida antibodies in both men and women by indirect immunofluorescence, but they used porcine rather than primate zonae pellicidae [27]. Normal animal and human serum are known to contain a wide range of low-titer autoantibodies that have been termed "natural autoantibodies" [28]. Even B cells from newborn mice and human cord blood produce these natural autoantibodies [29-31]. The low titer ovarian antibodies that we demonstrate here in the serum of normal women are likely natural autoantibodies, and not antibodies with any pathophysiologic significance.

Identifying women with autoimmune premature ovarian failure presents the opportunity to restore ovarian function by proper immune modulation therapy. However, at present we don't really know how many women with premature ovarian failure develop it due to autoimmunity. Currently, ovarian biopsy is the only way to diagnose autoimmune premature ovarian failure with certainty. However, because there is no treatment proven safe and effective to restore fertility, in our view, ovarian biopsy is not indicated outside a controlled trial [17].

\section{Conclusions}

We found that approximately one-third of women with normal ovarian function have ovarian autoantibodies detected by indirect immunofluorescence using monkey ovary as substrate. Hence, this ovarian antibody test as presently performed has poor specificity, and therefore appears to have no benefit in the evaluation and management of autoimmune premature ovarian failure. The specificity of any ovarian antibody test should be established before it is used clinically.

\section{Competing interests}

None declared.

\section{Authors' contributions}

J.A.N. and Z-B.T. participated in the design of the study and carried out the laboratory investigation. All authors participated in the analysis of the data and the preparation of the manuscript. L.M.N. conceived the study, participated in its design and coordination, recruited the patients, and was responsible for their evaluation and clinical care. All authors read and approved the final manuscript.

\section{Acknowledgements}

We thank Rene Kimzey, RN for help in recruitment, patient care and protocol coordination. SNK was the recipient of a scholarship by the Alexandros S. Onassis Public Benefit Foundation

\section{References}

I. Bannatyne P, Russell P and Shearman RP Autoimmune oophoritis: a clinicopathologic assessment of 12 cases. Int J Gynecol Pathol 1990, 9:191-207

2. Irvine WJ, Chan MMW, Scarth L, Kolb FO, Hartog M and Bayliss RIS Immunological aspects of premature ovarian failure associated with idiopathic Addison's disease. Lancet 1968, 2:883-890

3. Sedmak DD, Hart WR and Tubbs RR Autoimmune oophoritis: a histopathologic study of involved ovaries with immunologic characterization of the mononuclear cell infiltrate. Int J Gynecol Pathol 1987, 6:73-81

4. Kalantaridou SN, Braddock DT, Patronas NJ and Nelson LM Treatment of autoimmune premature ovarian failure. Hum Reprod 1999, I4:1777-1782

5. Smith S and Hosid S Premature ovarian failure associated with autoantibodies to the zona pellucida. Int J Fertil Menopausal Stud 1994, 39:316-319

6. Case Records of the Massachusetts General Hospital (Case 46-1987) N Engl J Med 1987, 3 I 7:1270-1278

7. Wheatcroft NJ, Salt C, Milford-Ward A, Cooke ID and Weetman AP Identification of ovarian antibodies by immunofluorescence, enzyme-linked immunosorbent assay or immunoblotting in premature ovarian failure. Hum Reprod 1997, I 2:2617-2622

8. Kalantaridou SN, Davis SR and Nelson LM Premature ovarian failure. Endocrinology and Metabolism Clinics of North America 1998, 27:989- 1005

9. Rebar RW, Erickson GF and Yen SSC Idiopathic premature ovarian failure: clinical and endocrine characteristics. Fertil Steril 1982, 37:35-41

10. Nelson LM, Anasti JN, Kimzey LM, Defensor RA, Lipetz KJ and White BJ Development of luteinized Graafian follicles in patients with karyotypically normal spontaneous premature ovarian failure. J Clin Endocrinol Metab 1994, 79: |470-| 475

II. Szlachter BN, Nachtigall LE, Epstein J, Young BK and Weiss G Premature menopause: a reversible entity? Obstet Gynecol 1979 , 54:396-398

12. Alper MM, Jolly EE and Garner PR Pregnancies after premature ovarian failure. Obstet Gynecol 1986, 67:59s-62s 
13. Kreiner D, Droesch K, Navot D, Scott R and Rosenwaks Z Spontaneous and pharmacologically induced remissions in patients with premature ovarian failure. Obstet Gynecol 1988, 72:926-928

14. Santoro $N$ and Schmidt $C$ Pregnancy after an unsuccessful oocyte donation cycle. Fertil Steril 1990, 53:174-176

15. Grimes DA Introducing evidence-based medicine into a department of obstetrics and gynecology. Obstet Gynecol 1995, 86:45I-457

16. Coulam CB and Ryan RJ Premature menopause, I. Etiology. Am J Obstet Gynecol I 979, I33:639-643

17. Nelson LM, Anasti JN and Flack MR Premature Ovarian Failure. In Reproductive Endocrinology, Surgery, and Technology (Edited by: Adashi EY, Rock JA, Rosenwaks Z) New York: Raven Press 1995, I393-1410

18. Belvisi $L$, Bombelli $F$, Sironi $L$ and Doldi N Organ-specific autoimmunity in patients with premature ovarian failure. J Endocrinol Invest 1993, 16:889-892

19. Kirsop R, Brock CR, Robinson BG, Baber RJ, Wells JV and Saunders DM Detection of anti-ovarian antibodies by indirect immunofluorescence in patients with premature ovarian failure. Reprod Fertil Dev 199I, 3:537-54 I

20. DeMoraes-Ruehsen M, Blizzard RM, Garcia-Bunuel R and Jones GS Autoimmunity and ovarian failure. Am J Obstet Gynecol 1972, I I 2:693-703

21. Ishizuka B, Kudo Y, Amemiya A, Yamada H, Matsuda $T$ and Ogata $T$ Anti-nuclear antibodies in patients with premature ovarian failure. Hum Reprod 1999, 14:70-75

22. Miyake T, Taguchi O, Ikeda $H$, Sato $Y$, Takeuchi $S$ and Nishizuka $Y$ Acute oocyte loss in experimental autoimmune oophoritis as a possible model of premature ovarian failure. Am J Obstet Gynecol 1988, 158:186-192

23. Rhim SH, Millar SE, Robey F, Luo AM, Luo YH and Yule T Autoimmune disease of the ovary induced by a ZP3 peptide from the mouse zona pellucida. J Clin Invest 1992, 89:28-35

24. Tong $Z B$ and Nelson LM A mouse gene encoding an oocyte antigen associated with autoimmune premature ovarian failure. Endocrinol 1999, 140:340 I-3403

25. Tong ZB, Gold L, Pfeifer KE, Dorward H, Lee E and Bondy CA Mater, a maternal effect gene required for early embryonic development in mice. Nat Genet 2000, 26:267-268

26. Tong ZB, Bondy CA, Zhou J and Nelson LM A human homologue of mouse Mater, a maternal effect gene essential for early embryonic development. Hum Reprod 2002, 17:903-91।

27. Sacco AG and Moghissi KS Anti-zona pellucida activity in human sera. Fertil Steril 1979, 3 I:503-506

28. Schwartz RS Autoimmunity and Autoimmune Diseases. In Fundamental Immunology (Edited by: Paul WE) New York: Raven Press 1993. 1033-1097

29. Pisetsky DS, Jelinek DF, McAnally LM, Reich CF and Lipsky PE In vitro autoantibody production by normal adult and cord blood B cells. J Clin Invest 1990, 85:899-903

30. Levinson Al, Dalal NF, Haidar M and Tar L Prominent IgM rheumatoid factor factor production by human cord blood lymphocytes stimulated in vitro with Staphylococcus aureus Cowan I. J Immunol 1987, 139:2237-224 I

31. Underwood JR, Pedersen PJ and Chalmers PJ Hybrids from normal, germ-free, nude, and neonatal mice produce monoclonal antibodies to eight different intracellular structures. Clin Exp Immunol 1995, 60:417-426

\section{Pre-publication history}

The pre-publication history for this paper can be accessed here:

http://www.biomedcentral.com/1472-6874/3/2/prepub Publish with BioMed Central and every
scientist can read your work free of charge

"BioMed Central will be the most significant development for disseminating the results of biomedical research in our lifetime. "

Sir Paul Nurse, Cancer Research UK

Your research papers will be:

- available free of charge to the entire biomedical community

- peer reviewed and published immediately upon acceptance

- cited in PubMed and archived on PubMed Central

- yours - you keep the copyright

Submit your manuscript here:

http://www.biomedcentral.com/info/publishing_adv.asp
BioMedcentral 